\title{
Music and emotion in Alzheimer's disease
}

\author{
Eva M. Arroyo-Anlló ${ }^{1,4^{*}}$, Stéphanie Dauphin², M. Noelle Fargeau², Pierre Ingrand ${ }^{3}$ and Roger Gil ${ }^{4}$
}

\begin{abstract}
Background: Alzheimer's disease may compromise several musical competences, though no clear data is available in the scientific literature. Furthermore, music is capable of communicating basic emotions, but little is known about the emotional aspect of music in patients with Alzheimer's disease. We present a systematic investigation of music processing in relation to extra-musical skills, in particular emotional skills in patients with Alzheimer's disease.

Methods: We tested 30 patients with mild or moderate Alzheimer's disease and 30 control subjects. We essentially evaluated (a) musical competences, using the extra-linguistic test, Solfeggio test and the recognition test of musical emotions - elaborated by our research team - and the Seashore test, and (b) emotional capacities using emotional memory and emotional prosody tests - made by our research group.

Results: We significantly observed lower total results of every test assessing cognitive, emotional and music competences in Alzheimer's disease patients than those in control subjects, but the score of musical emotion recognition test did not reach to a significant difference between the subjects groups.

Conclusions: Our findings found a global impairment of music competences in Alzheimer patients with cognitive and emotional troubles. Nevertheless, the performances in the recognition test of musical emotions showed a trend towards a performance difference. We can suggest that Alzheimer's disease currently presents an aphaso-agnosoapractic-amusia syndrome.
\end{abstract}

Keywords: Emotion, Music, Dementia, Memory, Prosody

\section{Introduction}

The capacity to perceive, experience and produce music is a fundamentally human characteristic, present universally across different cultures [1]. Music needs a complex information processing, requiring the analysis of a musical stimulus target against the acoustic background, representation of the musical source (instrumental or vocal timbre) and tracking of pitch (melody) and temporal (rhythm, metre) information, as well as music memory (for review, see [2]).

Alzheimer's disease (AD) is a degenerative neuropathology characterized by a progressive decline in cognitive and behavioural functions, due to a progressive posterior atrophy, in particular of medial temporal lobes. AD may compromise several musical competences, though no clear data are available in the scientific literature. Several studies have found impaired tone recognition [3], pitch

\footnotetext{
* Correspondence: anlloa@usal.es

${ }^{1}$ Department of Psychobiology, Neuroscience Institute of Castilla-León, University of Salamanca, Av. de la Merced s/n 37007, Salamanca, Spain ${ }^{4}$ Emeriti Professor of Neurology, University Hospital, Poitiers, France Full list of author information is available at the end of the article
}

perception and tonal working memory [4-9], timbre [10] or rhythm [11] in AD patients, but other studies have observed relatively preserved ability to detect basic acoustic changes in music as pitch $[10,12,13]$, timbre or rhythm $[8,14]$.

Concerning musical memory in $\mathrm{AD}$, most studies have observed relatively spared with familiar music [13, 15-19], depending more on semantic musical memory. In contrast, heterogeneous results have been found using unfamiliar music [8, 19-25], exploring more episodic musical memory.

Furthermore, music is capable of communicating basic emotions [26], which are recognized effortlessly in adults and regardless of musical training [27]. Despite much recent interest in music and emotion, little is known about emotional aspect of the music in patients with $A D$. In contrast, recognition for facial, visual or vocal expressions of emotion has been more studied in $\mathrm{AD}$ [27-29]. In general, most studies on emotion in AD have observed that emotion is not completely abolished, because patients are able to remember better the words with emotional valence than neutral ones or to 
remember better autobiographical events with greater emotional charge [30].

Concerning musical emotions, studies with AD patients have found that they can perceive and recognize emotions conveyed by music as well as recognize the melodies and titles of familiar songs [4, 12, 13, 31, 32]. Familiar music has an enormous power to evoke personal emotions and memories [32]. Several neuroimaging studies in dementia groups have found that impaired recognition of musical emotions appears to be related to the degree of atrophy specifically in the anterior temporal lobe, which is more common in semantic dementia than in $\mathrm{AD}[12,13,33,34]$.

In order to let us understand the relations between musical and emotional competences in $\mathrm{AD}$, we present a systematic investigation of music processing in relation to extra-musical skill, in particular emotional skills in patients with Alzheimer's disease.

\section{Material and methods Subjects}

We studied 60 subjects, including 30 patients diagnosed with Alzheimer's disease and 30 normal healthy controls. All participants were native French speakers and interested in music, but not music professionals. They were right handed and had no hearing problems.

Thirty patients with a clinical diagnosis of probable Alzheimer's disease were recruited at the Department of Neurology and Neuropsychology, University Hospital, CHU La Milétrie at Poitiers, France. They lived at home with a family caregiver. All AD patients had a history of progressive decline in intellectual function without focal motor or sensory features. To exclude other possible causes of dementia, appropriate laboratory tests were performed and these gave normal results. No findings incompatible with a diagnosis of $\mathrm{AD}$ were found in the electroencephalogram, electrocardiogram or chest X-ray in any of the patients. Brain CT scan revealed mild cortical and central atrophy, but no other pathology. All Alzheimer patients met the diagnostic criteria of the "NINCDS - ADRDA Work Group" and of the DSM-5. All had a score of less than 5 on the Hachinski Ischemic Scale. According to the Clinical Dementia Rating System (CDR) [35] and Mini-Mental State Examination (MMS), 13 patients had mild AD and 17 patients had moderate $\mathrm{AD}$. All $\mathrm{AD}$ subjects were taking anti-dementia medication during the study, in particular anti-acetyl cholinesterase treatments. Only the AD patients whose verbal comprehension (assessed by the MMS three-stage command) were equal to or above 2 were included in the study.

Controls primarily comprised of volunteers from French community or were members or visitors at the University Hospital in Poitiers (France) whose results in a neurological examination were normal, had a Clinical Dementia Rating
Scale (CDR) equal to 0 and scored $28 / 30$ or higher on the Mini-Mental Status Examination (MMS).

\section{Material}

Neuropsychological assessment consisted of testing (a) cognitive and mood states, as well as emotional capacities, and (b) musical competences.

\section{A. Cognitive and emotional assessments}

On the one hand, we used the Mini-Mental State Examination (MMS) to assess cognitive aspects and The Hospital Anxiety and Depression Scale (HAD) of Zigmond y Snaith [36] for anxiety-depression evaluation.

On the other hand, we assessed the emotional capacities using two tests elaborated by our research team: (a) emotional memory test and (b) test of emotional prosody. Concerning the first test evaluating emotional memory, it consisted of the learning of two lists of words, one of sixteen words with negative emotional connotation (list A: e.g. corpse, disease...) which are matched in length and frequency with another list of sixteen neutral emotional words (list B: e.g. place, shape...). The goal is to compare the learning of an emotionally negative word list to learning emotionally neutral word list, in order to understand the impact of the emotion aspect on episodic learning. We ask them to learn each list of words over five successive trials (assessing the encoding ability and learning) and a long delay free recall is made $20 \mathrm{~min}$ later. The emotional memory score reflects the impact of the words emotion on learning and it was the words' total of five trials in list B minus the total of the five trials from list A.

Concerning the test of emotional prosody, it is composed of three subtests, evaluating the spontaneously intonation expression, repetition of an intonation and recognition of emotional prosody, using the recorded sentences. Each sentence was recorded technically with Apple's Logic Pro 8 and was presented via over-ear ATHM30 professional headphones from Audio-Technica (http://www.audio-technica.com) in the same order for all participants. In the absence of an objective measure of auditory acuity, participants were asked during a preevaluation example to adjust the volume to a comfortable and clearly audible level. In stimulus presentation, the minimum selected headphone volume proved to be between 65 and 70 decibels $(\mathrm{dB})$ and the maximum between 80 and $85 \mathrm{~dB}$. The first subtest consisted of spontaneously producing a sentence with a proper emotion in function of the context. We used four kinds of emotions: joy, sadness, anger and neutral (e.g. The attitude of an employee is unacceptable, the boss tells him [context]: "I'm fed up and more than fed up, next time it's the door"). The second subtest consisted on intonation repetition of a sentence, using three semantically neutral sentences 
presented with four different intonations-joy, sadness, anger and neutral. The third subtest consisted of the identification of the sentence emotion (joy, sadness, anger and neutral). We used 12 sentences, three for each emotion type and each sentence could be heard twice, but we considered the first answer done by subject to score. All responses were recorded to assess later for independent examiners. The criteria for the rating of the first two subtests was carefully determined by two of the examiners as perfect (two points), partly perfect (one point) and incorrect (no points). The maximum score of each sentence was one point across the test and the maximum scores of each subtest were 12 points, respectively.

\section{B. Musical competences' assessment}

We evaluated the musical competences using four tests: extra-linguistic test, Solfeggio test, recognition test of musical emotions and Seashore test [37]. The first three tests were elaborated by our research team, taking account of the western tonal system. The selected music tracks are listened to for about a minute and the response time is 1 min maximum.

Concerning the extra-linguistic test, it assessed three aspects: (a) recognition of six rhythmic structures, (b) eight musical items of familiar and unfamiliar melodic memory and (c) recognition of five musical timbres. Firstly, participants had to identify the musical style that they have recognized in a total of six extracts listened to-one extract per musical style (Tango/Waltz/Paso doble/Slow/Walk/Rock). Secondly, subjects had to identify and repeat the total of five very traditional French songs (e.g. "Mon beau sapin"/"Les rois mages"...). They had to say the title of the familiar melody they think they had recognized, because they previously sang or hummed this in the air. After that, they must identify one melody which is not familiar, which has been previously listened to, among two other melodies. And thirdly, all subjects must recognize a total of five different musical timbres and name the musical instrument they recognized in the musical excerpt broadcast (Piano/Guitar/Organ/Hunting Horn/Violin). The maximum total score of the test was 19 points, a point for each correct musical item.

Concerning the Solfeggio test, it was composed of two subtests: the recognition of twenty notes and the writing of fifteen notes. The maximum score of each correct note was one point and the total score was 35 points.

In addition, we also performed the Seashore test (for instructions and items, see [37]), in order to also evaluate the musical competences. This test contains six measurements for which we take only the first ten items of each subtest as follows: (a) sense of pitch interval (10 pairs of tones differing in frequency from 17 to $2 \mathrm{~Hz}$; the subject was asked whether the second tone is higher or lower than the first); (b) sense of loudness (10 pairs of tones differing in intensity from 4.0 to $0.5 \mathrm{~dB}$; the subject was asked whether the second tone was stronger or weaker than the first); (c) sense of rhythm (10 pairs of rhythmic patterns; the subject was asked whether they are the same or different); (d) sense of time (10 pairs of tones differing in duration by 0.3 to $0.5 \mathrm{~s}$; the subject was asked whether the second was longer or shorter than the first); (e) sense of timbre (10 pairs of tones, each of which was made up of the fundamental first five harmonic intervals with the intensities of the third and fourth harmonies being varied; the subject was asked whether they were the same or different; and (f) tonal memory (10 pairs of tone sequences with one tone different in the second sequence as compared to the first; the subject was asked which tone is different). The score was one point per exact answer, and the maximum total score was 60 points.

Regarding the musical emotion recognition test, we previously proposed to recognize the emotion evoked by 12 extracts of musical pieces (4 pieces per emotion-joy, fear or sadness) to 84 young people, in order to choose the extracts, whose emotion was clearly recognized by more than $90 \%$ of them. For that, we used the following opened question, in order to allow them to freely communicate the feelings evoked by each musical piece: "How do you feel by listening to these music excerpts?". We noted for each musical extract, the words that inspired them and when the emotion was clearly recognized, the notation was joy, fear or sadness. Thus, we could only select 6 musical extracts according to three primary emotions-2 extracts per emotion: (a) joy ("The Four Seasons-Spring" by Vivaldi and "Folies Bergère" from Paul Lincke, which have been recognized 100\% as joy emotion by the young group), (b) sadness ("The Funeral March" of Chopin and "The Dispute" of Yann Tiersen: 90\% and 97\%, respectively) and (c) fear ("The theme of Psychosis" by Bernard Herrmann and "The theme of Teeth of the Sea" by John Williams: 97\%). After that, we used those six musical extracts in the musical emotion recognition test. All participant groups had the following instruction for each musical extract: "Choose-on the sheet-the emotion in which it makes him think of joysadness-fear". The maximum score was 6 points (one point per correct answer).

\section{Procedure}

The assessment was carried out along a one-week period in 2 sessions, each one in two different days. The first session was for the evaluation of cognition, mood and emotional capacities, and the second one was exclusively for assessing the musical competences. All participants were tested individually in two sessions with the same 
order of testing. Each session took between 45 and $60 \mathrm{~min}$ to complete.

\section{Statistical analyses}

Data was analysed using the Statistical Package SASsoftware version 9.2. In this study, an $\alpha$ level of 0.05 was selected for statistical significance. To find significant differences in gender and laterality distributions among the groups, we used the non-parametric test of Fisher, and in age, mood state, educational and musical level, we used the non-parametric test of Kruskal-Wallis.

To compare the mean scores of musical and emotional capacities between participant groups, the Wilcoxon or Kruskal-Wallis test was used. We also used Spearman's correlation analysis to analyse the relationships between the music competences and cognitive-emotional aspects.

\section{Results}

\section{Demographic characteristics}

Sixty subjects participated in the study: two experimental groups, one of 13 patients with mild $\mathrm{AD}$ (MiAD) and another with 17 patients had moderate $\mathrm{AD}$ (MoAD), and a control group of 30 healthy subjects.

Concerning the experimental AD groups (19 women and 11 men), the mean duration of the disease was 3.2 years for MiAD and 4.9 years for MoAD. The MiAD group (7 women and 6 men) had a mean age $( \pm$ SD) of 74.8 years old $( \pm 3.58)$, a MMS score $( \pm$ SD) of $23.8( \pm 2.91)$ and a mean educational level $( \pm$ SD) of $4.12( \pm 0.39)$ using the classification of Barbizet and Duizabo [38]: illiterate (educational level (EL) 1), able to read, to write and to count (EL 2), 6 years of education (EL 3), 9 years of education (EL 4), 11 or 12 years of education (EL 5), 13 years of education (EL 6) and more than 13 years of education (EL 7). The MiAD patients had a mean musical level $( \pm \mathrm{SD})$ of $1.30( \pm 0.15)$ using the classification of Sol [39]: no musical learning or playing instrument (musical level (ML)1), music theory learning or playing instrument for 1 year (ML2), regular music theory learning or playing instrument for 2 to 5 years (ML3), regular music theory learning or playing instrument for 6 to 10 years (ML4), high music studies and/or performed in concert (ML5), currently performing live in concerts (ML6). The MoAD group (12 women and 5 men) had a mean age $( \pm$ SD) of 76.1 years old $( \pm 2.93)$, a MMS score $( \pm$ SD) of $14.9( \pm 2.20)$, a mean educational level $( \pm$ SD) of $3.97( \pm 0.61)$ using the classification of Barbizet and Duizabo [38] and a mean musical level $( \pm$ SD) of 1.51 $( \pm 0.11)$ using the classification of Sol [40].

Concerning the control group (18 women and 12 men), the mean age $( \pm$ SD) was of 75.9 years old $( \pm 1.30)$. It had a MMS score $( \pm$ SD) of $28.6( \pm 1.22)$, a mean educational level $( \pm$ SD) of $3.99( \pm 0.24)$ using the classification of
Barbizet and Duizabo [38] and a mean musical level $( \pm$ SD) of $1.21( \pm 0.30)$ using the classification of Sol [39].

There were no significant differences in gender $(p=$ $0.56)$, laterality $(p=1)$, age $(p=0.14)$ and educational $(p=0.40)$ and musical $(p=0.78)$ level distributions among the groups. The clinical and demographic data of the participating groups are shown in Table 1.

\section{Cognitive and emotional aspects}

Concerning cognitive state (Table 1), we found a significant difference between three participant groups for MMS score $(p=0.0018)$, as well as between the MiAD and MoAD groups $(p=0.007)$. In regard to mood state assessed by the HAD test, the MiAD group had an anxiety subtest score $( \pm \mathrm{SD})$ of $5.2( \pm 2.9)$ and a depression subtest score of $3.5( \pm 2.4)$ and the MoAD group had an anxiety subtest score $( \pm \mathrm{SD})$ of $5.2( \pm 4.2)$ and a depression subtest score of $3.2( \pm 1.8)$, and so, the control group had an anxiety subtest score $( \pm$ SD) of $6.6( \pm 2.8)$ and a depression subtest score of $3.4( \pm 1.8)$. All groups did not differ significantly between them (anxiety subtest: $p=0.18$; depression subtest: $p=0.62$ ).

Regarding the emotional capacities, the analysis of the results shows a significant difference between the three groups for the emotional memory test $(p<0.0001$; Table 2), both for the list of emotionally charged words (list A) and for the list of emotionally neutral words (list B). All AD patients had lower scores for every word list learning and long delay free recall than the control group. We also observed a significant difference of emotional memory score between all participant groups $(p=$ $0.0086)$, as well as between the control and MiAD groups $(p=0.012)$, but not between AD groups $(p=0.068)$ for the emotional memory (Table 2). Wilcoxon analysis showed that learning and delayed recall performances were worse between the control group and MiAD group $(p \leq 0.0002)$. However, MiAD had better learning than MoAD, but the long delay free recall performances are similar between both groups $(p>0.05$; Table 2$)$.

There was a significant difference for the emotional prosody test between the three participant groups (Table 2). The performances of every subtest of this emotional prosody test were statistically lower in $\mathrm{AD}$ groups than those of the control group (spontaneous intonation expression: $p=$ 0.0005; intonation repetition: $p=0.0036$ and recognition of sentence emotion: $p=0.0185$ ). However, the Wilcoxon test showed only significant difference for intonation spontaneous expression between the MiAD and control groups $(p=0.0230)$.

\section{Musical competences}

In general, we significantly found lower total scores of every test assessing music competences in $\mathrm{AD}$ patients than those in control subjects, except for the score of 
Table 1 Means (M) and standard deviations (SD) of several demographic and clinical characteristics of the AD and control groups

\begin{tabular}{|c|c|c|c|c|}
\hline & MiAD group & MoAD group & Control group & \\
\hline & $\mathrm{M}(\mathrm{SD})$ & $M(S D)$ & $M(S D)$ & $p$ value \\
\hline Sample size $(N)$ & 13 & 17 & 30 & \\
\hline Gender (M:F) & $6: 7$ & $5: 12$ & $12: 18$ & $>.05$ \\
\hline Age (years) & $74.80(3.58)$ & $76.11(2.93)$ & $75.92(1.30)$ & $>.05$ \\
\hline Educational level & $4.12(0.39)$ & $3.97(0.61)$ & $3.99(0.24)$ & $>.05$ \\
\hline Musical level & $1.30(0.15)$ & $1.51(0.11)$ & $1.21(0.30)$ & $>.05$ \\
\hline Mini-Mental State & $23.80(2.91)$ & $14.90(2.20)$ & $28.60(1.22)$ & $<.05^{*}$ \\
\hline Hospital Anxiety and Depression Scale & $\begin{array}{l}\text { Anxiety: } 5.2(2.9) \\
\text { Depression: } 3.5 \text { (2.4) }\end{array}$ & $\begin{array}{l}\text { Anxiety: } 5.2(4.2) \\
\text { Depression: } 3.2(1.8)\end{array}$ & $\begin{array}{l}\text { Anxiety: } 6.6 \text { (2.8) } \\
\text { Depression: } 3.4 \text { (1.8) }\end{array}$ & $>.05$ \\
\hline
\end{tabular}

${ }^{a} p$ values referred to control and experimental groups

*Significant difference $(p<.05)$

musical emotion recognition test which did not reach to a significant difference between the subject groups (Fig. 1 and Table 3).

There were significant differences in total scores of extra-linguistic and Solfeggio tests between the 3 participant groups. The extra-linguistic performances of the MiAD and MoAD groups showed more impairment to that of the control group (MiAD and MoAD: mean \pm standard deviations: $8.3 \pm 3.7$ and $7.3 \pm 3.0$, respectively vs. $13.5 \pm 4.3 ; p=0.0002$ ), as well as in the Solfeggio test (MiAD and MoAD: mean \pm standard deviations: $24.2 \pm$ 10.7 and $19.8 \pm 11.7$, respectively vs. $31.3 \pm 5.3 ; p=$ $0.0022)$. In Table 3 , it may be seen that significant differences were found in every aspect of the extra-linguistic test (rhythm recognition, melody memory and timbre recognition) between the three participant groups ( $p=$ $0.0013, p<0.013$ and $p=0.0025$, respectively). However, we did not observe a significant difference in the note recognition subtest of the Solfeggio test between the subject groups $(p=0.137)$, but it was found in the notes written subtest $(p=0.0001$; Table 3$)$. Furthermore, the extra-linguistic test significantly distinguished MiAD from control participants $(p=0.0027)$, but not MiAD from MoAD patients $(p=0.3560)$. In contrast, the Solfeggio test did not significantly differ between the MiAD and control subjects $(p=0.0552)$.

All AD patients also had worse performances in the Seashore test than the control group (MiAD and MoAD: mean \pm standard deviations: $37.5 \pm 6.4$ and $25.9 \pm 10.2$, respectively vs. $42.1 \pm 9.3 ; p<0.0001)$ and in its subtests, except for that of pitch sense $(p=0.061)$; (Table 3$)$. However, we did not find significant differences in the Seashore test between the MiAD and control groups $(p>$ 0.07 ). But the Seashore test showed statistically significant differences between the MiAD and MoAD patients in most of the Seashore subtests, except for pitch sense again (rhythm: $p=0.0393$; time: $p=0.0068$; timbre: $p=$ 0.0081 ; tonal memory: $p=0.0340)$, as well as in its total score $(p=0.0019)$. Furthermore, we found a significant correlation between the extra-linguistic and Seashore

Table 2 Means (M) and standard deviations (SD) of both emotional capacity tests (emotional memory and emotional prosody tests) in the $A D$ and control groups

\begin{tabular}{|c|c|c|c|c|}
\hline & MiAD group & MoAD group & Control group & \\
\hline & $M(S D)$ & $M(S D)$ & $M(S D)$ & $p$ value ${ }^{a}$ \\
\hline \multicolumn{5}{|l|}{ Emotional memory test } \\
\hline Total learning of emotionally charged word list (list A) & $26.3(5.5)$ & $17.7(6.5)$ & $47.4(13.2)$ & $<0.0001^{*}$ \\
\hline Total learning of emotionally neutral word list (list B) & $21.1(5.1)$ & $14.5(5.1)$ & $38.4(14.1)$ & $<0.0001^{*}$ \\
\hline Long delay free recall of list $A$ & $2.2(2.2)$ & $0.8(0.9)$ & $10.0(3.6)$ & $<0.0001^{*}$ \\
\hline Long delay free recall of list $B$ & $0.8(1.6)$ & $0.2(0.8)$ & $7.3(4.0)$ & $<0.0001^{*}$ \\
\hline Emotional memory score & $5.2(5.7)$ & $3.2(4.5)$ & $9.0(7.9)$ & $0.0086^{*}$ \\
\hline \multicolumn{5}{|l|}{ Emotional prosody test } \\
\hline Spontaneously intonation expression & $9.6(2.2)$ & $8.5(2.2)$ & $11.1(1.1)$ & $0.0005^{*}$ \\
\hline Intonation repetition & $29.4(5.9)$ & $14.5(5.1)$ & $33.1(3.8)$ & $0.0036^{*}$ \\
\hline Recognition of sentence emotion & $8.6(2.4)$ & $7.8(2.1)$ & $9.8(2.6)$ & $0.0185^{*}$ \\
\hline
\end{tabular}

${ }^{a} p$ values (Kruskal-Wallis test) referred to control and experimental groups

*Significant difference $(p<.05)$ 


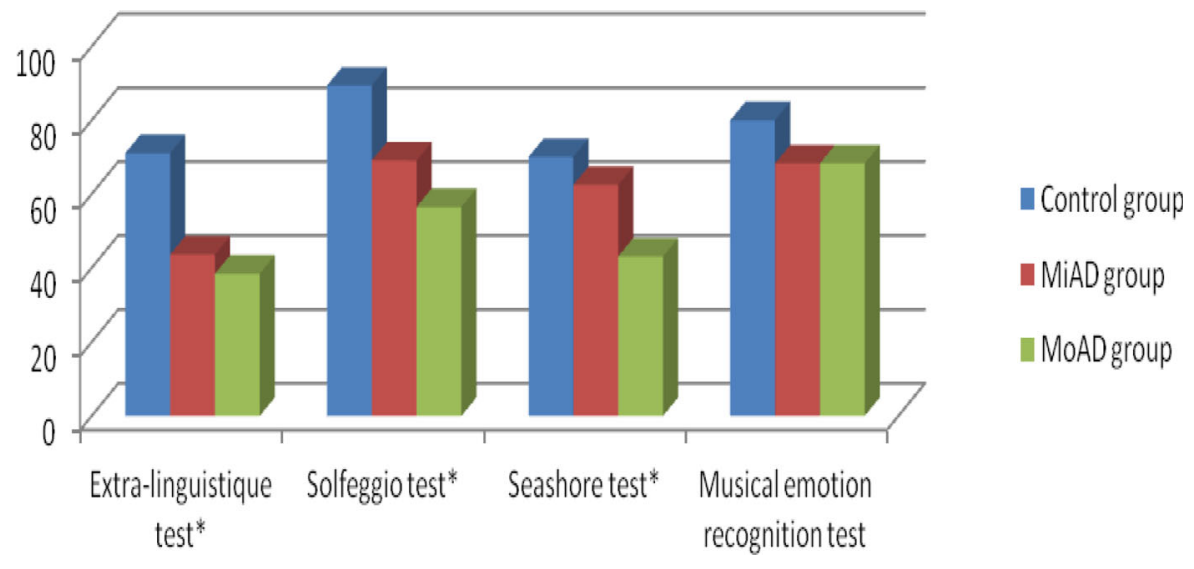

\section{${ }^{*}$ Significant difference $(p<.0023)$}

Fig. 1 Percentages of good answers in musical competences' tests for the AD and control groups. * Significant difference $(p<.0023)$

tests in all participant groups $(r=0.416 ; p=0.022)$. But considering the three shared items in both music tests (rhythm, timbre and tonal memory), only the timbre item showed an important correlation $(r=0.444 ; p=$ 0.013). Besides, significant correlations were found between the Seashore and MMS tests $(r=0.595 ; p=$ $0.0005)$, sentence emotion recognition of the emotional prosody test $(r=0.421 ; p=0.020)$ and the emotional memory test, but only for the emotional word list-list A $(r>0.505 ; p<0.0045)$. Besides, the Solfeggio test had

Table 3 Means (M), percentages and standard deviations (SD) of the extra-linguistic, Solfeggio and Seashore tests as well as the musical emotion recognition test in the $A D$ and control groups

\begin{tabular}{|c|c|c|c|c|}
\hline \multirow{3}{*}{ Extra-linguistic test } & \multirow{2}{*}{$\begin{array}{l}\text { MiAD group } \\
M \pm S D(\% \pm \% S D)\end{array}$} & \multirow{2}{*}{$\begin{array}{l}\text { MoAD group } \\
M \pm S D(\% \pm \% S D)\end{array}$} & \multicolumn{2}{|l|}{ Control group } \\
\hline & & & \multirow[t]{2}{*}{$\mathrm{M} \pm \mathrm{SD}(\% \pm \% \mathrm{SD})$} & $p$ value $^{a}$ \\
\hline & & & & \\
\hline Recognition of rhythmic structures & $1.9 \pm 1.4(31.7 \pm 23.3)$ & $1.6 \pm 1.2(26.7 \pm 20)$ & $3.9 \pm 1.9(65 \pm 31.7)$ & $0.0013^{*}$ \\
\hline Familiar melody memory & $2.4 \pm 1.2(48 \pm 24)$ & $2.6 \pm 1.1(52 \pm 22)$ & $3.4 \pm 1.0(68 \pm 20)$ & $0.0126^{*}$ \\
\hline No familiar melody recognition & $1.5 \pm 0.8(50 \pm 26.7)$ & $1.1 \pm 1.0(36.7 \pm 33.3)$ & $2.4 \pm 0.7(80 \pm 23.3)$ & $0.0002^{*}$ \\
\hline Recognition of musical timbres & $2.4 \pm 1.4(48 \pm 28)$ & $2.0 \pm 1.4(40 \pm 28)$ & $3.7 \pm 1.5(74 \pm 30)$ & $0.0025^{*}$ \\
\hline Total score & $8.3 \pm 3.7(43.6 \pm 19.5)$ & $7.3 \pm 3.0(38.4 \pm 15.8)$ & $13.5 \pm 4.3(71.1 \pm 22.6)$ & $0.0002^{*}$ \\
\hline \multicolumn{5}{|l|}{ Solfeggio test } \\
\hline Notes recognition & $15.3 \pm 6.9(72.8 \pm 32.9)$ & $13.9 \pm 7.4(66.2 \pm 35.2)$ & $18.7 \pm 4.3(89 \pm 6.2)$ & $0.1370 \mathrm{~ns}$ \\
\hline Notes writing & $8.8 \pm 4.8(62.9 \pm 34.3)$ & $5.9 \pm 5.0(42.1 \pm 35.7)$ & $12.6 \pm 1.7(90 \pm 12.1)$ & $0.0001^{*}$ \\
\hline Total score & $24.2 \pm 10.7(69.1 \pm 30.6)$ & $19.8 \pm 11.7(56.6 \pm 33.4)$ & $31.3 \pm 5.3(89.4 \pm 15.1)$ & $0.0022^{*}$ \\
\hline \multicolumn{5}{|l|}{ Seashore test } \\
\hline Pitch & $5.5 \pm 2.4(55 \pm 24)$ & $4.4 \pm 2.2(44 \pm 22)$ & $6.5 \pm 2.4(65 \pm 24)$ & $0.0610 \mathrm{~ns}$ \\
\hline Loudness & $6.2 \pm 2.5(62 \pm 25)$ & $4.4 \pm 2.9(44 \pm 29)$ & $7.5 \pm 2(75 \pm 20)$ & $0.0027^{*}$ \\
\hline Rhythm & $7.3 \pm 2.7(73 \pm 27)$ & $5.5 \pm 2.4(55 \pm 24)$ & $7.9 \pm 1.9(79 \pm 19)$ & $0.0089^{*}$ \\
\hline Time & $7.7 \pm 1.7(77 \pm 17)$ & $5.2 \pm 2.7(52 \pm 27)$ & $7.7 \pm 2(77 \pm 20)$ & $0.0043^{*}$ \\
\hline Timbre & $6.8 \pm 1.6(68 \pm 16)$ & $4.6 \pm 2.4(46 \pm 24)$ & $6.6 \pm 2(66 \pm 20)$ & $0.0090^{*}$ \\
\hline Tonal memory & $3.9 \pm 2.3(39 \pm 23)$ & $2.1 \pm 1.9(21 \pm 19)$ & $6 \pm 3.2(60 \pm 32)$ & $0.0008^{*}$ \\
\hline Total score & $37.5 \pm 6.4(62.5 \pm 10.7)$ & $25.9 \pm 10.2(43.1 \pm 17)$ & $42.1 \pm 9.3(70.1 \pm 15.5)$ & $<0.0001^{*}$ \\
\hline Musical emotion recognition test & $4.1 \pm 1.3(68.3 \pm 21.6)$ & $4.1 \pm 0.8(68.3 \pm 13.3)$ & $4.8 \pm 1.4(80 \pm 23.3)$ & $0.0634 \mathrm{~ns}$ \\
\hline
\end{tabular}

${ }^{a} p$ values (Kruskal-Wallis test) referred to control and experimental groups

*Significant difference $(p<.05)$

ns no significant difference 
also a significant correlation to recognition of sentence emotion of the emotional prosody test $(r=0.524 ; p=$ $0.0029)$, as well as the list A learning $(r=0.399 ; p=$ 0.0287). We also found a significant correlation between the extra-linguistic score and intonation repetition of the emotional prosody test $(r=0.406 ; p=0.025)$, as well as the list A learning $(r=0.448 ; p=0.012)$.

Concerning the musical emotion recognition test (Fig. 1), the total score of the whole $\mathrm{AD}$ group was lower than that of the control group, without reaching to significant difference $(p=0.0634)$. But the performances were similar between the MiAD vs. MoAD groups (mean \pm standard deviations: $4.1 \pm 1.3$ vs. $4.1 \pm 0.8, p=$ 0.9826 ) and MiAD vs. control group (mean \pm standard deviations: $4.1 \pm 1.3$ vs. $4.8 \pm 1.4, p=0.1187$ ). Considering each kind of primary emotions (joy, sadness and fear; Fig. 2), all $A D$ patients recognized the joy emotion of musical excerpts as well as control participants (two joy musical excerpts: $93 \%$ and $97 \%$ vs. $95 \%$ and $100 \%$ ) and something less the sad emotion of music $(67 \%$ and $73 \%$ vs. $81 \%$ and $81 \%$ ). However, the fear emotion of music was more difficult to recognize by $\mathrm{AD}$ patients than by the control group ( $47 \%$ and $30 \%$ vs. $62 \%$ and $57 \%$ ).

\section{Discussion}

The main goal of this study was to evaluate the music processing in relation particularly to emotional skill in AD, using a musical protocol including musical skills' tests (extra-linguistic, Solfeggio and Seashore tests) and a musical emotion recognition test. Thus, we compared the music competences between two groups of patients with AD-MIAD and MoAD—and a control subject group, which they did not significantly differ in gender, laterality, age, educational and musical levels, as well as mood state, but $\mathrm{AD}$ patients showed the important cognitive and emotional deficits.

In general, the findings seem to suggest that global weakening of musical processing is a common disorder in $\mathrm{AD}$. The results showed the lower performances of musical competences in $\mathrm{AD}$ groups than in the control group, assessing by the extra-linguistic, Solfeggio and Seashore tests.

The extra-linguistic performances were altered in MiAD patients, but it did not significantly decrease over the disease severity. The extra-linguistic aspects (recognition of rhythmic structures, melody memory and recognition of musical timbres) essentially put into play the capacities of working and long-term memory, reflecting the classical results about more important progressive deficit of short-term memory and learning than autobiographical memory [40]. We found the important verbal learning deficit and cognitive impairment in AD groups, though we did not include an auditory working memory test in our study which could have improved our results analysis. Several works have demonstrated that music memory is relatively preserved in patients with moderate to severe $\mathrm{AD}$ in spite of otherwise severe overall impairment $[16,17]$. However, some reports have described impaired music memory in $\mathrm{AD}[20,21,23]$. Besides, several studies have showed that recognition memory was better for the novel sung than spoken lyrics in $A D$ patients $[22,24,25]$. Familiarity of music also is another aspect taken into account to explain the variability of music memory in $\mathrm{AD}$ patients [2, 18, 33, 41, 42]. In this sense, the recent study of Slaterry et al. [42] found out that in AD patients, unfamiliar melodies depended more on episodic memory, involving disease-associated activation group differences in precuneus and posterior cingulate

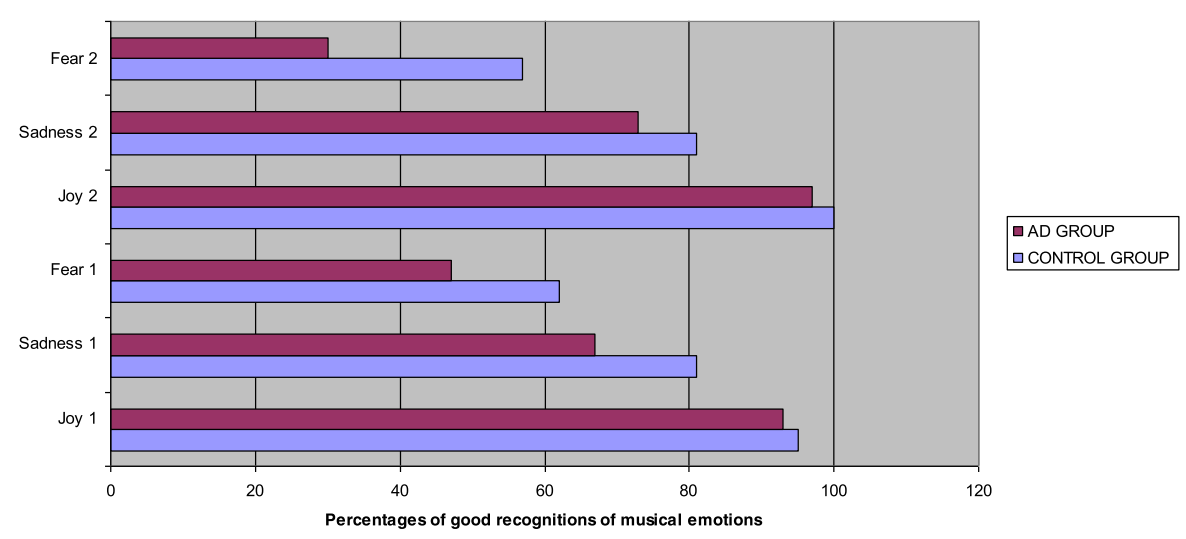

1: first musical excerpt of each emotion (ex. Joy 1).

2: second musical excerpt of each emotion (ex. Joy 2).

Fig. 2 Percentages of good recognition of musical emotions in music excerpts produced by the AD and control groups. 1: First musical excerpt of each emotion (e.g. Joy 1). 2: Second musical excerpt of each emotion (e.g. Joy 2) 
cortex, and familiar melodies depended more on semantic memory, involving activation differences in right inferior frontal cortex. In addition, Baird and Samson [18] suggested that perhaps the implicit and procedural memories for musical stimuli remain preserved, but not musical episodic memory. Regarding neural basis, emotion and implicit memory share neural subcortical structures, such as the amygdales or basal ganglia, which are ontogenetically older than those of explicit memories. Furthermore, we found important and progressive deficits of the word lists learning in $\mathrm{AD}$ patients, more with the emotionally neutral word list than that with emotionally charged words. We also noted a positive emotional impact of words on learning (emotional memory score) in $\mathrm{AD}$ groups, despite the difficulties of memory. However, the emotional effect on learning was less important than that of the control group.

Concerning the Solfeggio test, we observed similar results for note recognition subtest between the participant groups, but not for the note writing subtest. Similar results were found by Sol [39]. This result could be explained in terms of the task difficulty degree. The cognitive competences of the note recognition subtest are similar to those of language recognition tasks, but not for note written subtest. In this last subtest, patients rewrote the name of the note in words on the music sheet instead of drawing it or they randomly placed notes on the music sheet. Nevertheless, we must also consider the praxis, spatial organization or understanding troubles in $\mathrm{AD}$ patients, explaining those results, but we did not find a relationship between MMS and Solfeggio scores.

However, we only found a significant correlation between MMS and Seashore scores, which assess essentially basic acoustic changes in music. The performances of the Seashore test progressively decreased from MiAD to MoAD patients, except for pitch interval as others studies have observed, too [10, 43]. The work of Golden et al. [10] also observed an unimpaired sense of pitch interval, but it found a selective deficit of global pitch (melody contour). They suggest that this deficit might be due to auditory working memory deficits and, thus, it might reflect increased demand for coordinated integrative computations between temporo-parietal association cortices vulnerable to AD [44]. The results showed that music aspects of time, rhythm and timbre were more initially resistant to the AD, before dropping to the moderate stage. However, the tonal memory was early altered in the MiAD patients, and then it decreased more in MoAD group. Most of Seashore subtests significantly differentiated the MiAD group from MoAD group, but it did not distinguish the MiAD group from that of the control. The Seashore test would therefore be sensitive to the evolution of the disease, but it could not discriminate effectively the MiAD patients from healthy subjects. In contrast, the extra-linguistic test could distinguish control and MiAD participants, but not between the AD stages. Besides, we found a strong relationship between Seashore and extra-linguistic tests, and so, it lets you choose one of them for evaluations of musical abilities, but taking into account that the extra-linguistic score is composed of more ecological items and faster assessment than those of the Seashore test.

Furthermore, the Seashore and Solfeggio tests showed the strong correlations with the emotional prosody recognition and emotional learning, suggesting that the musical abilities depend on emotional aspects. In our study, emotional prosody can also distinguish control subjects and $\mathrm{AD}$ patients, but the most sensitive item to detect MiAD from healthy participants was spontaneous production of intonation. This result suggests the presence of an expressive emotional aprosody from early stage of AD. The similar results were observed by Roberts et al. [45], concerning the early troubles of emotional production, but they also found preserved emotional prosody recognition in patients with $\mathrm{AD}$. Thus, the emotional perceptual aspect would play a more important role in the preservation/impairment of the musical competences than the emotional expressive aspect.

Concerning the musical emotion recognition test, the performances are poorer in $\mathrm{AD}$ patients than those of control participants, though the results did not reach to be significantly different between them, despite the cognitive and emotional troubles in the AD groups. Thus, we can observe a trend towards a performance difference between $\mathrm{AD}$ and control subjects, though both $\mathrm{AD}$ groups showed the similar results. It could also be suggested that processing of musical emotion may be relatively more resistant than other musical skills to $\mathrm{AD}$, as it has previously been observed in other studies $[4,31]$. In addition, several studies have also found the similar results using familiar or not familiar music [12, 15, 30, 31]. However, it is necessary to consider a limitation in our work, to the future studies, concerning the small size of items used in this test of musical emotion recognition, because a larger stimulus set with a greater range may have more clearly exposed a deficit. Furthermore, the recognition capacity of musical emotions was not the same for every type of emotion in our study. All participants recognized the joy emotion of music, followed by sadness emotion, but the fear emotion seemed more difficult to recognize from the music pieces by all groups. Fear is a very complex emotional expression and several studies also observed similar results for fear emotion recognition vs. joy and sadness emotions from faces [29, 40, 46]. Recognition impairments for facial expressions of emotion are seen in $\mathrm{AD}[27,28]$ and more altered in semantic dementia. Nevertheless, some studies $[4,46]$ found unimpaired performances in recognition of non-familiar facial and non-familiar musical emotions in $\mathrm{AD}$. 
Moreover, Hsieh et al. [32] observed the common neural substrates supporting the processing of emotions by facial and musical stimuli, involving essentially the right temporal pole, amygdala and insula, but the recognition of musical (but not facial) emotions was also associated with the left anterior and inferior temporal lobe, which are associated with semantics in language. In this sense, the work of Omar et al. [34] observed deficient recognition of emotions from music as well as faces and voices in subjects with frontotemporal lobar degeneration. They observed that the impaired recognition of emotions from music was specifically associated with grey matter loss in a distributed cerebral network including the insula, orbitofrontal cortex, anterior cingulate and medial prefrontal cortex, anterior temporal and more posterior temporal and parietal cortices, amygdala and the subcortical mesolimbic system.

It is also necessary to consider other limitation in our study, concerning the possible semantic associations in some items of musical emotion recognition, for instance, in the case of the fear emotion which can be associated to a movie theme or any other association of an emotion and past experiences. These associations require interactions between musical emotions and music processing. Nevertheless, AD groups showed the important declarative memory troubles. It will be interesting to use a larger item size and to control the semantic associations of musical pieces in future studies analysing musical processing in $\mathrm{AD}$.

Moreover, the preservation/impairment is heterogeneous in the different aspects of musical abilities in $\mathrm{AD}$, essentially due to the diffuse nature of the neural musical network which relies on the participation of the two cerebral hemispheres and in relation to melodic and temporal processing of the functional architecture model by Peretz and Coltheart [47]. The two cerebral hemispheres would be solicited in musical cognition and the preserved or not capacities are indifferent in one or the other. The diffuse nature of the musical neural network would probably be an asset in the relative preservation of certain musical skills. For instance, it is found in the right cerebral hemisphere the time, the timbre, and the joy and sadness recognitions which are mostly preserved at the beginning of the disease. In contrast, the left hemisphere is more responsible for the notions of rhythm, musical reading and the naming and identification of familiar music. This last ability was slightly less affected than other musical skills, maybe due to the relatively good semantic memory and emotional aspect of familiar melodies. We suggested that the emotional perceptive aspect seems to retain certain music skills, which are more resistant than other musical skills to AD. In this sense, several studies have also found an expressive aprosody in the early stages of $\mathrm{AD}$ (for review, see [48].

\section{Conclusions}

The present findings have certain practical and clinical implications. This study observed a global deterioration of musical abilities in AD patients. Nevertheless, the performances of musical emotions' recognition in both $\mathrm{AD}$ groups are poorer than those of the control group, but they did not reach statistical significance. Thus, we can suggest that $\mathrm{AD}$ currently presents an aphaso-agnosoapractic-amusia syndrome. Further studies are necessary to improve the limitations observed in this study in order to deep in the musical processing in AD. And future study cohorts should ideally encompass a wider range of $\mathrm{AD}$ and other neurodegenerative diseases with longitudinal assessments to determine the sensitivity and specificity of particular musical patterns, associated to histopathological and molecular data. Besides, the present data underline the need to take into account individual variability, which may be amplified by prior musical competence, in order to deeper delineate the alterations in brain mechanisms of music processing produced by $\mathrm{AD}$.

The results of this study also suggest that it is possible to make a fast assessment of the subject's musical abilities, considering three musical scores: extra-linguistic, Solfeggio and emotional recognition scores. We consider that the Seashore test could be reserved only to deeply complete the musical profile of the subject. Furthermore, our data also suggest that the power of emotional music could enhance the general mental state in a more direct and involuntary neural network, and it could enhance more using music related to the personal experience of the subject. Future studies could find more evidences about the benefits of emotion and music powers on mental health in neurodegenerative diseases, in particular in accessing emotional memories.

\section{Abbreviations \\ AD: Alzheimer's disease; CDR: Clinical Dementia Rating Scale; EL: Educational level; HAD: The Hospital Anxiety and Depression Scale; MiAD: Mild Alzheimer's disease; ML: Musical level; MMS: Mini-Mental Status Examination; MoAD: Moderate Alzheimer's disease}

\section{Acknowledgements}

The authors thank the patients and subjects for participating in this study.

\section{Authors' contributions}

EA-A, RG, SD and MNF are responsible for data acquisition, analysis and interpretation. PI is responsible for the design and conduct of analysis data. All authors read and approved the final manuscript.

\section{Funding}

This study was not sponsored. All authors are current full-time employees or students of the University of Salamanca, Spain, or University Hospital at Poitiers, France. We used the resources of both institutions. 


\section{Availability of data and materials}

All data and material is available at the Department of Neurology of University Hospital, CHU La Milétrie, Poitiers, France.

\section{Ethics approval and consent to participate}

The study was approved by The Regional Committee for Research Ethics, $\mathrm{CHU}$ Poitiers.

\section{Consent for publication}

All authors consent the study for publication. Written and informed consent was obtained from all the included patients.

\section{Competing interests}

The authors declare that they have no competing interests.

\section{Author details}

'Department of Psychobiology, Neuroscience Institute of Castilla-León, University of Salamanca, Av. de la Merced s/n 37007, Salamanca, Spain. ${ }^{2}$ Department of Neurology Faculty of Medicine, University Hospital, CHU La Milétrie, 2, Rue de la Milétrie, 86021 Poitiers, France. ${ }^{3}$ Department of Biostatistics Faculty of Medicine, University of Poitiers, 2, Rue de la Milétrie, 86021 Poitiers, France. ${ }^{4}$ Emeriti Professor of Neurology, University Hospital, Poitiers, France.

Received: 17 March 2019 Accepted: 22 July 2019

Published online: 07 August 2019

\section{References}

1. Fritz $\mathrm{T}$, Jentschke $\mathrm{S}$, Gosselin $\mathrm{N}$, et al. Universal recognition of three basic emotions in music. Curr Biol. 2009;19:1-4.

2. Särkämö T, Sihvonen AJ. Golden oldies and silver brains: deficits, preservation, learning, and rehabilitation effects of music in ageing-related neurological disorders. Cortex. 2018;109:104-23.

3. Strouse AL, Hall JW, Burger MC. Central auditory processing in Alzheimer's disease. Ear Hear. 1995;16:230-8.

4. Omar R, Hailstone JC, Warren JE, et al. The cognitive organization of music knowledge: a clinical analysis. Brain. 2010;133:1200-13.

5. Kurylo DD, Corkin S, Allard T, et al. Auditory function in Alzheimer's disease. Neurology. 1993;43:1893-9.

6. Goll JC, Kim LG, Ridgway GR, et al. Impairments of auditory scene analysis in Alzheimer's disease. Brain. 2012:135(Pt. 1):190-200.

7. Golden HL, Agustus JL, Nicholas JM, et al. Functional neuroanatomy of spatial sound processing in Alzheimer's disease. Neurobiol Aging. 2016;39: 154-64

8. Campanelli A, Rendace L, Parisi F, et al. Musical cognition in Alzheimer's disease: application of the Montreal Battery of Evaluation of Amusia. Ann N Y Acad Sc. 2016:1375(1):28-37.

9. White DA, Murphy CF. Working memory for nonverbal auditory information in dementia of the Alzheimer type. Arch Clin Neuropsychol. 1998;13:339-47.

10. Golden HL, Clark CN, Nicholas JM, et al. Music perception in dementia. J Alzheimers Dis. 2017;55(3):933-49.

11. Beatty WW. Preserved cognitive skills in dementia: implications for geriatric medicine. J Okla StateMed Asso. 1999;92:10-2.

12. Johnson JK, Chang CC, Brambati SM, et al. Music recognition in frontotemporal lobar degeneration and Alzheimer disease. Cogn Behav Neurol. 2011;24:74-84

13. Hsieh $S$, Hornberger M, Piguet $O$, Hodges JR. Neural basis of music knowledge: evidence from the dementias. Brain. 2011;134(Pt. 9):2523-34.

14. Cowles A, Beatty WW, Nixon SJ, et al. Musical skill in dementia: a violinist presumed to have Alzheimer's disease learns to play a new song. Neurocase. 2003;9:493-503.

15. Basaglia-Pappas S, Laterza M, Borg C, et al. Exploration of verbal and non-verbal semantic knowledge and autobiographical memories starting from popular songs in Alzheimer's disease. Int Psychogeriatr. 2013:25:785e795.

16. Cuddy LL, Duffin J. Music, memory, and Alzheimer's disease: ismusic recognition spared indementia and how can it be assessed? Med Hypotheses. 2005;64:229-35.

17. Vanstone $A D$, Cuddy $L L$, Duffin JM, Alexander E. Exceptional preservation of memory for tunes and lyrics case studies of Amusia, profound deafness, and Alzheimer's disease. Neurosciences and Music lii. 2009:1169:291-4.

18. Baird A, Samson S. Music and dementia. Prog Brain Res. 2015;217:207-35.

19. Cuddy LL, Duffin JM, Gill SS, et al. Memory for melodies and lyrics in Alzheimer's disease. Music Percept. 2012;29:479-91.

20. Quoniam N, Ergis AM, Fossati P, et al. Implicit and explicit emotional memory for melodies in Alzheimer's disease and depression. Ann N Y Acad Sci. 2003;999:381-4.

21. Menard MC, Belleville S. Musical and verbal memory in Alzheimer's disease: a study of long-term and short-term memory. Brain Cogn. 2009;71(1):38-45.

22. Moussard A, Bigand E, Belleville S, Peretz I. Learning sung lyrics aids retention in normal ageing and Alzheimer's disease. Neuropsychol Rehabil. 2014;24:894e917.

23. Halpern AR, O'Connor MG. Implicit memory for music in Alzheimer's disease. Neuropsychology. 2000;14(3):391-7.

24. Palisson J, Roussel-Baclet C, Maillet D, et al. Music enhances verba episodic memory in Alzheimer's disease. J Clin Exp Neuropsychol. 2015:37:503e517.

25. Simmons-Stern NR, Budson AE, Ally BA. Music as a memory enhancer in patients with Alzheimer's disease. Neuropsychologia. 2010;48: 3164e3167

26. Peretz I. Towards Neurobiology of Musical Emotions. In: Juslin PN, Sloboda JA, editors. Handbook of Musican d'Emotion: Theory, Research, Applications. NewYork: Oxford University Press; 2010. p. 99-126.

27. Bediou B, Ryff I, Mercier B, et al. Impaired social cognition in mild Alzheimer disease. J Geriatr Psychiatry Neurol. 2009;22:130-40.

28. Hargrave R, Maddock RJ, Stone V. Impaired recognition of facial expressions of emotion in Alzheimer's disease. J Neuropsychiatry Clin Neurosci. 2002;14: 64-71.

29. Brosgole L, Kurucz J, Plahovinsak T, et al. Facial-affect recognition in normal preschool children and in senile elderly persons. Int J Neurosci. 1983;20(12):91-102.

30. Koelsch S. Towards a neural basis of music-evoked emotions. Trends Cogn Sci. 2010;14:131-7.

31. Drapeau J, Gosselin N, Gagnon L, et al. Emotional recognition from face, voice, and music in dementia of the Alzheimer type. Ann N Y Acad Sci. 2009:1169:342-5.

32. Hsieh S, Hornberger M, Piguet O, Hodges JR. Brain correlates of musical and facial emotion recognition: evidence from the dementias. Neuropsychologia. 2012;50:1814-22.

33. Arroyo-Anlló EM, Poveda Díaz J, Gil R. Familiar music as an enhancer of selfconsciousness in patients with Alzheimer's disease. J Biomed Biothechnol. 2013;1:1-10.

34. Omar R, Henley SM, Bartlett JW, Hailstone JC, Gordon E, Sauter DA, Frost C, Scott SK, Warren JD. The structural neuroanatomy of music emotion recognition: evidence from frontotemporal lobar degeneration. Neurolmage. 2011;56:1814-21.

35. Hughes $C P$, Berg $L$, Danziger $W L$, et al. A new clinical scale for the staging of dementia. Br J Psychiatry. 1982;140:566-72.

36. Zigmond AS, Snaith RP. The hospital anxiety and depression scale. Acta Psychiatr Scand. 1983;67:361-70.

37. Seashore C, Lewis D, Saetveit J. Seashore measures of musical talents manual. Rev. Ed. New York: Psychological Corporations; 1960.

38. Barbizet J, Duizabo P. Neuropsychologie. Paris: Masson; 1985.

39. Conway MA. Memory and the self. J Mem Lang. 2005;53:594-628.

40. Sol P. Musique et Maladie d'Alzheimer. Thèse Pour Le Doctorat En Médecine (No Published). Poitiers: University of Poitiers; 1993.

41. Peck KJ, Girard TA, Russo FA, Fiocco AJ. Music and memory in Alzheimer's disease and the potential underlying mechanisms. J Alzheimers Dis. 2016;51(4):949-59.

42. Slattery CF, Agustus JL, Paterson RW, McCallion O, Foulkes AJM, Macpherson K, Carton AM, Harding E, Golden HL, Jaisin K, Mummery CJ, Schott JM, Warren JD. The functional neuroanatomy of musical memory in Alzheimer's disease. Cortex. 2019;115:357-70.

43. Horley K, Reid A, Burnham D. Emotional prosody perception and production in dementia of the Alzheimer's type. J Speech Lang Hear Res. 2010:53(5):1132-46.

44. Burunat I, Alluri $V$, Toiviainen $P$, et al. Dynamics of brain activity underlying working memory for music in a naturalistic condition. Cortex. 2014;57:254-69. 
45. Roberts VJ, Ingram SM, Lamar M, Green RC. Prosody impairment and associated affective and behavioral disturbances in Alzheimer's disease. Neurology. 1996: 47(6):1482-8.

46. Torres Mendonça De Melo Fádel B, Santos De Carvalho RL, Belfort Almeida Dos Santos TT, Dourado MCN. Facial expression recognition in Alzheimer's disease: a systematic review. Clin Exp Neuropsychol. 2018:8:1-12.

47. Peretz I, Coltheart M. Modularity of music processing. Nat Neurosci. 2003:6(7):688-91.

48. Misiewicz S, Brickman AM, Tosto G. Prosodic impairment in dementia: review of the literature. Curr Alzheimer Res. 2018;15(2):157-63.

\section{Publisher's Note}

Springer Nature remains neutral with regard to jurisdictional claims in published maps and institutional affiliations.

Ready to submit your research? Choose BMC and benefit from:

- fast, convenient online submission

- thorough peer review by experienced researchers in your field

- rapid publication on acceptance

- support for research data, including large and complex data types

- gold Open Access which fosters wider collaboration and increased citations

- maximum visibility for your research: over $100 \mathrm{M}$ website views per year

At BMC, research is always in progress.

Learn more biomedcentral.com/submissions 